\title{
PROCESSO DE TRANSFORMAÇÃO DOS BAIRROS ESTREITO E BALNEÁRIO NA REGIÃO CONTINENTAL DE FLORIANÓPOLIS A PARTIR DA LEITURA DO PLANO URBANO
}

\section{PROCESS OF TRANSFORMATION OF THEESTREITO AND BALNEÁRIO NEIGHBORHOODS IN THE CONTINENTAL REGION OF FLORIANOPOLIS FROM THE READING OF THE URBAN PLANE}

\author{
Karine dos Santos Luiz (UFSC); \\ Adriana Marques Rossetto, Dra. (UFSC); \\ Anicoli Romanini, M.Sc. (UFSC). \\ Palavras Chave \\ Transformação urbana; Paisagem; Períodos morfológicos.

\section{Key Words} \\ UrbanTransformation; Landscape; Morphological periods.
}

\section{RESUMO}

A pesquisa busca compreender o processo de transformação e organização dos bairros Estreito e Balneário em Florianópolis a partir da análise de elementos morfológicos estruturantes da paisagem urbana. $\mathrm{O}$ artigo apresenta análise do plano urbano, a partir do método da visão tripartite, construído por M. G. R. Conzen, a partir de análises do plano urbano, tecido urbano e o uso do solo. O estudo da evolução do plano urbano, busca analisar a historicidade e identificar diferentes períodos morfológicos. Pesquisas bibliográficas e documentais; ortofotos e imagens de satélite e observações exploratórias em campo foram realizadas para o estudo da morfologia urbana. $O$ resultado revelou a historicidade e os períodos morfológicos urbano dos bairros que intercorrem por acelerado processo de transformação urbana. Com a investigação morfológica da cidade, foi possível resgatar a identidade do lugar a partir das formas urbanas, contribuindo para preservação da paisagem e para o planejamento urbano.

\section{ABSTRACT}

The research seeks to understand the process of transformation and organization of the Estreito and Balneário districts in Florianópolis from the analysis of morphological elements structuring the urban landscape. The article presents an analysis of the urban plan, used by on the vision tripartite method, constructed by M. G. R. Conzen, based on analyzes of the urban plan, urban fabric and land use. The study of the evolution of the urban plan, seeks to analyze the historicity and identify different morphological periods. Bibliographical and documentary research; orthophotos and satellite images and exploratory field observations were performed for the study of urban morphology. The result revealed the historicity and urban morphological periods of the districts that run through the accelerated process of urban transformation. With the morphological investigation of the city, it was possible to recover the identity of the place from the urban forms, contributing to its preservation landscape and urban planning. 


\section{INTRODUÇÃO}

Os melhoramentos urbanos advindos de projetos e obras de revitalização da orla marítima e a verticalização têm se tornado elementos predominantes e influentes na morfologia urbana de muitas cidades brasileiras. Esses elementos que se estruturam na paisagem são reflexos da sociedade urbana que se estabelece num período definido por Santos (1994) como meio técnico-científico-informacional. $\mathrm{O}$ urbano objeto de pesquisa definido por Léfèbvre (1999) se transforma a partir do tempo e espaço, nos quais a paisagem construída determina diferentes período da sociedade urbana que incorre novas formas urbanas nas cidades brasileiras. O que se apresenta hoje em muitos lugares da cidade, é que ela não revela o seu passado de forma explicita aos olhos e no dia-dia, mas este passado da cidade está ali, presente nos processos de construção das formas urbanas que constituíram a paisagem.

Assim, as modificações no desenho urbano, provocam alguns questionamentos com relação a história do lugar e da cidade. A pesquisa traz a perspectiva dos estudos morfológicos para a cidade Florianópolis aplicada nos bairros Estreito e Balneário, a partir da evolução do plano urbano. Na Figura 1 é apresentado a localização e recorte espacial da pesquisa na região continental de Florianópolis onde se localizam os bairros, que durante muitos anos teve sua configuração territorial sobre domínio da cidade de São José, cidade circunvizinha da Capital.

Somente no ano de 1943 está porção de terra passou a fazer parte da cidade de Florianópolis. De acordo com Soares (1990), até a década de 1950 a região do Estreito ainda apresentava características de comunidade rural. As primeiras ruas formadas no bairro surgiram de ocupações que visavam a defesa da llha, com a construção de fortificação, como o Forte São João construído no século XIX e também de moradias que tinham a função de casa de passagem para quando as condições meteorológicas na baía não fossem favoráveis para a travessia de embarcações.

Foi com a construção da Ponte Hercílio Luz no ano de 1926, que a dinâmica urbana desta região começou a apresentar as primeiras transformações morfológicas identificadas na paisagem e na dinâmica urbana A cidade que tinha a travessia do Continente para a llha realizada somente pelo mar, teve suas primeiras transformações morfológicas evidenciadas com a ampliação das vias para o automóvel e com isso o primeiro processo de expansão urbana se evidencia na região. No decorrer do século XX e XXI, o Estreito e Balneário apresentam na sua paisagem evidentes transformações morfológicas que geram a historicidade da formação socioespacial desta região.
Figura 1: Localização da área de pesquisa e recorte espacial

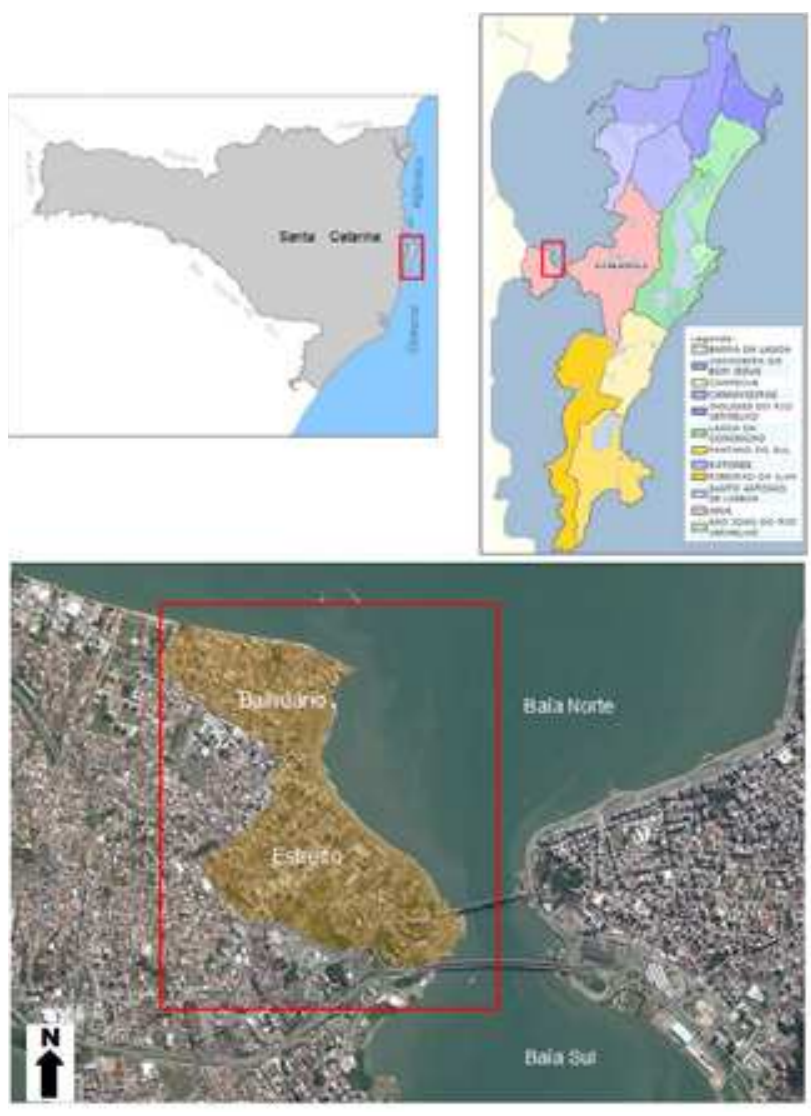

Fonte: Mapa físico de Santa Catarina, Secretaria de Planejamento; Mapa Distritos de Florianópolis, IPUF e Google Earth, 2017. Elaborado por Karine dos Santos Luiz,2017

Assim, a pesquisa busca resposta relacionada ao recente processo de transformação que se apresenta em curso, com o acelerado crescimento urbano condicionado pela construção do aterro da beira mar continental no ano de 2012. Como o processo de transformação urbana se apresenta em diferentes momentos (períodos) e lugares da cidade e o que determinam as transformações dos elementos urbanos? Deste modo, esta pesquisa tem como objetivo principal analisar o processo de transformação e organização dos bairros Estreito e Balneário em Florianópolis, a partir dos elementos morfológicos estruturantes, tendo como objetivos específicos analisar a historicidade dos bairros e identificar diferentes períodos morfológicos.

\section{REVISÃO BIBLIOGRÁFICA}

A forma urbana, objeto de estudo da morfologia urbana, permite a análise e identificação de elementos que são fundamentais para a melhor compreensão e leitura do traçado urbano e sua relação com a dinâmica urbana. De acordo com Levy (2005) a forma urbana foi abordada inicialmente por três escola de morfologia urbana (a 
italiana, a francesa e a inglesa), que utilizaram diferentes abordagens no estudo da forma no intuito de melhor compreender o espaço urbano.

A dinâmica das formas urbanas e a articulação entre esta forma e seus sentidos, possibilita a compreensão da sua natureza, de sua estrutura, de seu modo de produção e principalmente do modo como ocorre o processo de transformação nas cidades.

Os estudos de morfologia urbana da escola inglesa, apresentam relevante contribuição com o método de análise da forma urbana através da visão tripartite, que consiste no estudo do plano urbano, do tecido urbano e no padrão de uso e ocupação do solo. Conforme descreve Whitehand (2007), foi o Geógrafo alemão Michael Robert Günter Conzen, que desenvolveu a visão tripartite para aplicá-la nos estudos da forma urbana, considerando em primeiro lugar, o plano urbano (que compreende a topografia, ruas, parcelas e planos dos edifícios); em segundo lugar, a construção do tecido (a forma); e em terceiro lugar, como é a utilização da terra e da edificação.

Essas três dimensões de análise se justificam para elaboração de um método, pois conforme afirma Costa e Netto (2015 p.222), "em qualquer paisagem urbana estas categorias estão sempre presentes e associadas." O método da visão tripartite foi aplicado inicialmente nas pesquisas da escola inglesa de geografia de Birmingham, a partir do legado e estudos desenvolvidos por Conzen nesta escola. Com abordagem voltada ao planejamento urbano e regional, realizaram-se diversos estudos no âmbito da morfologia urbana, acerca da análise da paisagem urbana, elaborando mapeamento das várias formas físicas dentro da área urbana e classificando tipologias dos sítios e planos de uso do solo com o objetivo de conhecer o processo de transformação da paisagem.

Para Conzen, o plano urbano se conceitua na estrutura formal da cidade, e este expressa "a lógica da gênese do assentamento geográfico" (COSTA; NETTO, 2015 p.222).

Desta forma,

mesmo que ocorram mudanças na aparências das cidades, em relação ao seu sistema viário e ao parcelamento do solo, a investigação da transformação do lote demostra a capacidade das ruas de se adequarem à evolução urbana, ao longo dos séculos. Nesse sentido, a manutenção das formas representa o caráter das paisagens urbanas, estabelecido por meio das permanências, fruto das decisões humanas (COSTA; NETTO, 2015 p.222).
Ao associar o reconhecimento do tecido urbano com a apreensão direta das estruturas urbanas que auxiliam na leitura e análise da paisagem, estes facilitam a identificação de elementos urbanos, como as semelhanças das quadras, padrões de vias, lotes e edificações, para com obter-se respostas dos lugares onde efetuam-se as transformações e representam diferenciações no tecido urbano.

Para a escola inglesa de morfologia urbana no processo de transformação urbana existem elementos que repetem padrões semelhantes, e este aspecto possibilita a identificação como unidades características da forma urbana, onde estes se sobressaem em determinados períodos do tempo, determinando os denominados períodos morfológicos.

Com intuito de elaborar uma sistematização para os estudos de morfologia urbana, Conzen, a partir do estudo da forma urbana, estabelece a periodização para o estudo morfológico de setores da cidade. A partir dos estudos e princípios da escola inglesa de morfologia, a periodização é considerada importante instrumento de análise urbana que organiza as sequências temporais que apresentam as mudanças que fazem parte da história do lugar e da sociedade, e assim estabelecem as periodizações, ou seja os significados relacionados a períodos históricos e períodos evolutivos, que instituem e condicionam critérios de análise da forma urbana a partir da permanência, transformação e sobreposição das formas urbanas que revelam os traços da paisagem construída.

É importante destacar a definição dos períodos históricos e períodos evolutivos. Os períodos históricos são os fatos que são possíveis de delimitar datas (épocas), a partir de gestão de governos, períodos políticos, guerras, conflitos, crise econômicas, dentre outros. Os períodos evolutivos são datações a partir de convenções de acordo com documentos, fotos, mapas, imagens de satélite, fotografias aéreas ou qualquer indício físico que sirva de base para investigações acerca da transformação da paisagem urbana.

Diante do exposto, apreende-se que no processo de formação socioespacial e desenvolvimento da cidade, os períodos históricos e evolutivos produzem várias camadas de formas, que se acumulam e se sobrepõe em determinado espaço físico. Assim, os períodos históricos e evolutivos registram suas marcas, seus traços na paisagem e são reconhecidos por períodos morfológicos.

Para Costa e Netto $(2015$, p.69), ...

os períodos morfológicos são definidos como parte do processo de transformação cultural contínua, no qual a história geral e regional, a história do planejamento urbano, o urbanismo, a arquitetura, a tecnologia, a economia, e outros aspectos relevantes da cultura estão presentes. 
Assim, podemos considerar que a substituição de elementos urbanos nas cidades, nos revelam momentos históricos importantes do lugar. O crescimento urbano de algumas cidades brasileiras demostra a constante transformação dos seus espaços, sobretudo dos centros urbanos, onde sucessivas intervenções na paisagem modificam a forma urbana e as relações no espaço urbano.

\section{METODOLOGIA}

O método utilizado para reconhecimento e identificação dos períodos morfológicos na paisagem, foi orientado pela visão tripartite aplicado por Conzen que indica a periodização morfológica como método para reconhecimento das transformações na paisagem a partir de análise do plano urbano, tecido urbano e do uso e ocupação do solo, neste artigo a abordagem aprofundará a pesquisa relacionada ao plano urbano, a sua evolução e transformação.

Nesta análise buscou-se identificar elementos urbanos que apresentam padrões semelhantes da forma, definindo unidades características da forma urbana determinados pelos períodos do tempo, condicionados pela história e pela sociedade que o construiu, e assim determinam os denominados períodos morfológicos, confor-

Figura 2: Modelo de análise da Escola Inglesa de Morfologia Urbana.

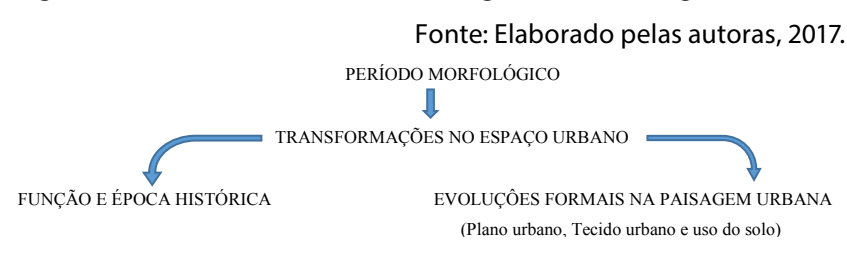

Para análise da área de estudo foram utilizadas as informações de referenciais teóricos e estudos de fontes direta e indiretas através de pesquisa bibliográfica, reconhecimento in loco da região analisada, além de busca de dados junto aos órgãos de planejamento urbano, patrimônio histórico de Florianópolis.

Foram utilizados dados do cadastro das ruas dos bairros, ortofotos do ano de 1938 a 2016 disponibilizadas pela Prefeitura Municipal de Florianópolis do geoprocessamento corporativo, para as análises morfológicas, bem como, imagens do Google Earth, para a realização das analises, leituras e mapeamento do plano urbano, sendo utilizado conjuntamente com o software AutoCad.

\section{RESULTADOS E DISCUSSÃO}

Os traços urbanos construídos na paisagem do Estreito e Balneário foram analisados a partir das ortofotos 1938 a 2016 (Figura 3) e conjuntamente com o levantamento histórico, foram identificados os períodos e suas determinantes histórica e evolução, conforme apresentado no Quadro 1.

\section{Figura 3: Ortofotos 1938 a 2016}

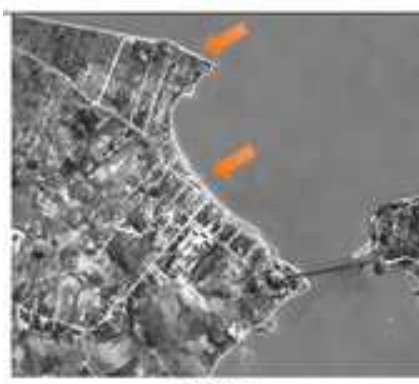

1938

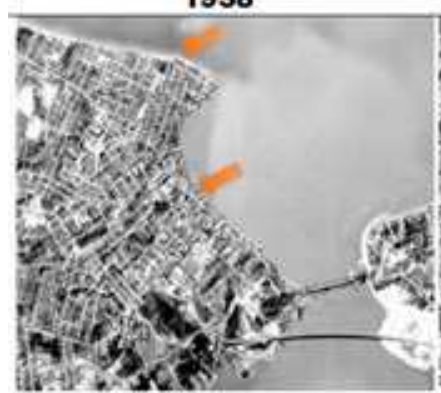

1977

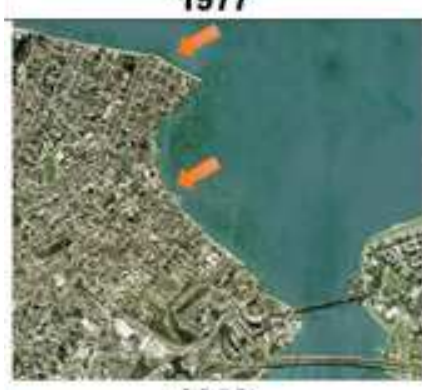

2002

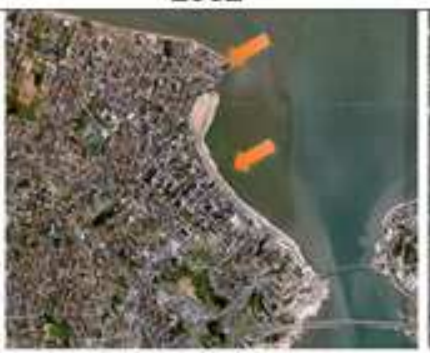

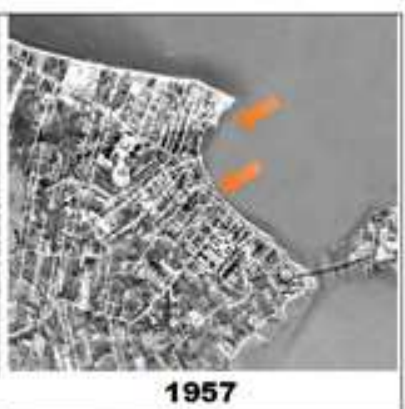

1957

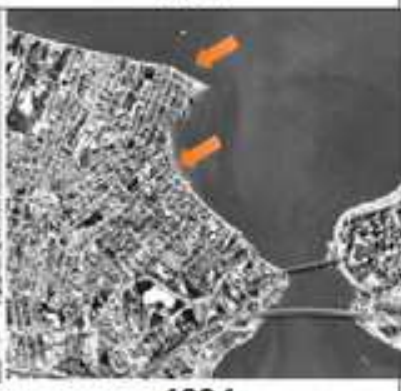

1994

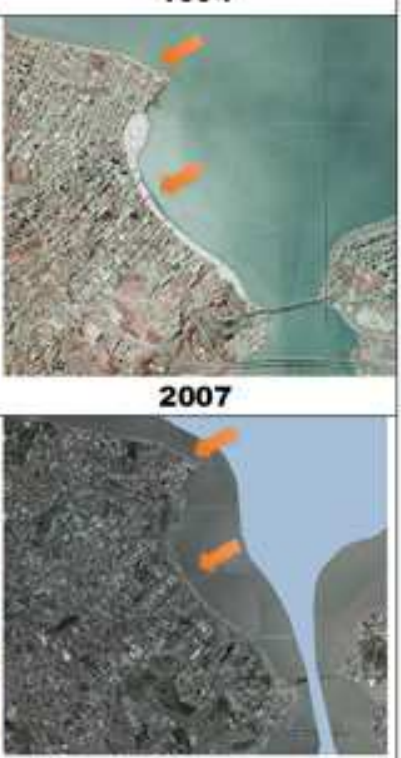

Fonte: PMF 
Quadro 1: Determinantes para a elaboração dos períodos morfológicos do Estreito e Balneário na região continental de Florianópolis.

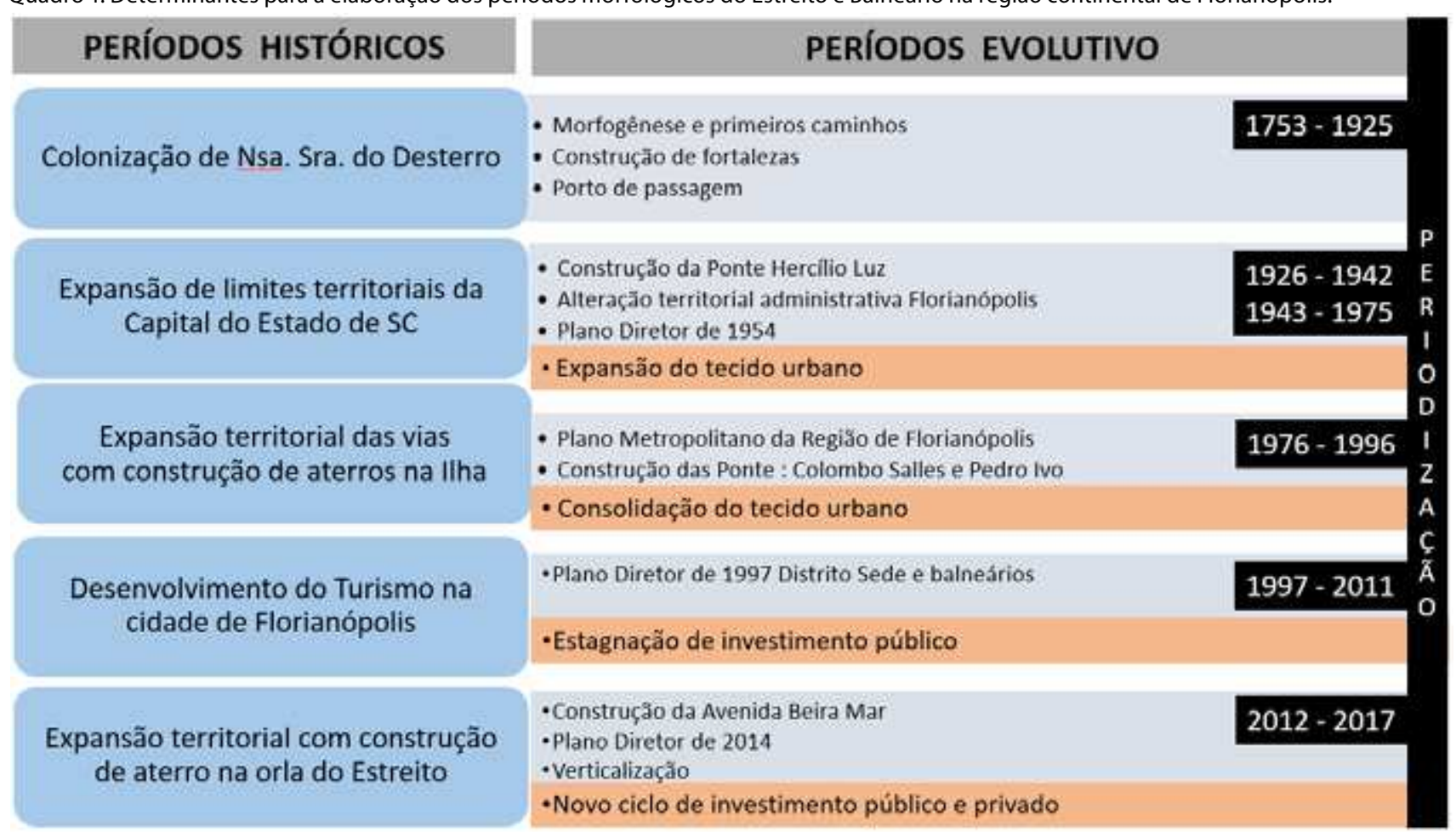

Fonte: Elaborado pelas autoras, 2017.

A construção desta periodização foi realizada a partir da análise do plano urbano e observações exploratórias através da análise dos elementos morfológicos: vias, lote e edificações, além de outros elementos marcos que estabeleceram rupturas para um próximo período, como a construção das pontes e o mais recente, o aterro da beira mar continental. Com as análises morfológica das vias construiu-se a periodização do plano urbano que é apresentada na Figura 4 e na Figura 5 o plano urbano é sistematizado através da periodização.

Figura 4: Períodos morfológicos categorização do plano urbano a partir das ortofotos.

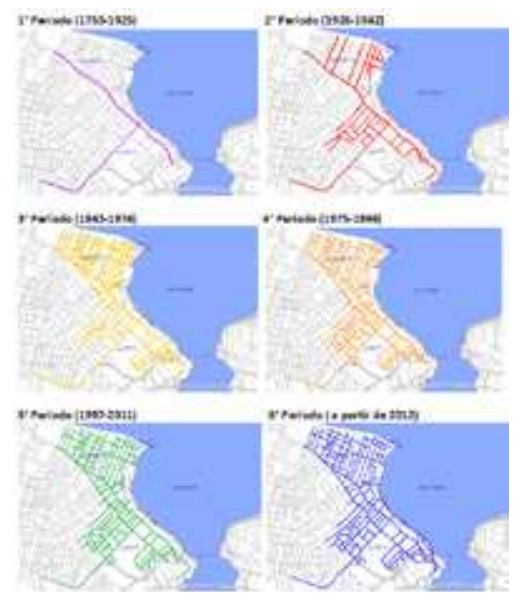

Fonte: Elaborado por Karine dos Santos Luiz, 2017
Figura 5: Periodização do plano urbano a partir das ortofotos.

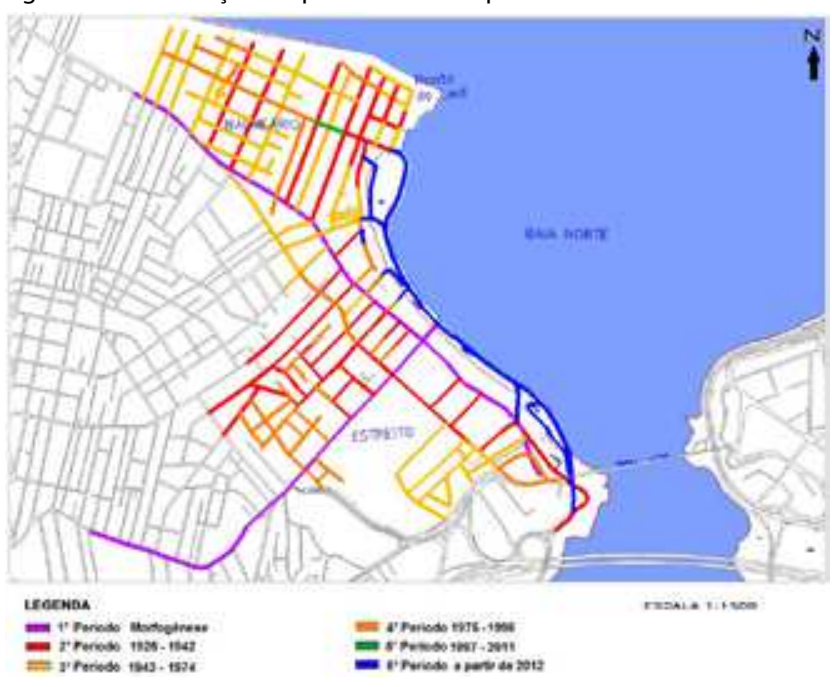

Fonte: Elaborado por Karine dos Santos Luiz, 2017.

Logo, com a periodização das vias e ocupações a partir da análise da evolução do plano urbano consegue indicar setores morfológicos que compõem a paisagem. Na Figura 6, são identificados no tecido urbano os setores do crescimento morfológico urbano do Estreito e Balneário. E, a partir desta análise busca-se verificar o que se apresentou no Quadro 1, relacionando a periodização das vias e ocupações (lotes) com os períodos evolutivos e períodos históricos. 
Figura 6: Mapa dos Setores do Crescimento morfológico urbano do Estreito e Balneário em Florianópolis.

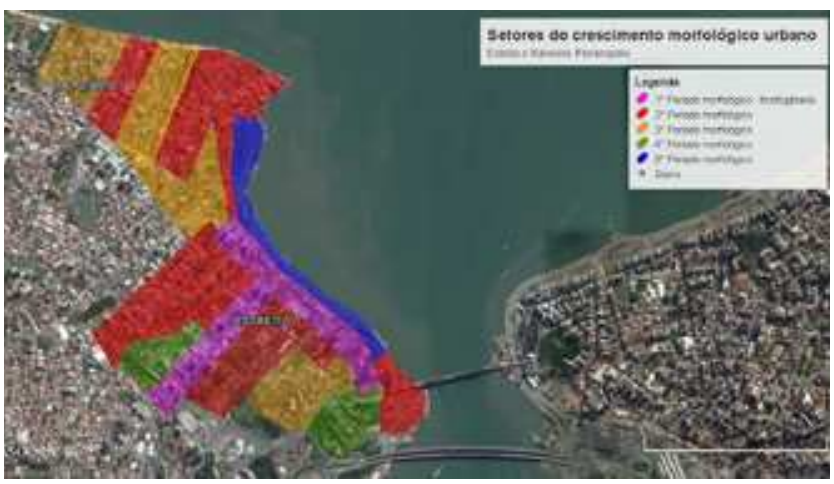

Fonte: Elaborado por Karine dos Santos Luiz, 2017.

Esta análise verifica que as principais transformações se efetivam a partir da introdução de elementos estruturantes, como a ponte Hercílio Luz que define a transição do período da morfogênese para o primeiro período morfológico, ou interferências diretas ou indiretas do planejamento urbano, como alterações territoriais, e elaboração de planos diretores.

Entretanto, as ações planejadas pelo poder público nesta região da cidade, não se efetivaram somente através de elaboração de planejamento urbano advindo das ações pública. O processo de construção e transformação da cidade, ocorre por interferência de novos elementos urbanos construídos na paisagem, a partir do parcelamento do solo para loteamento, remembramentos de lotes construção de pontes e vias (ruas e avenidas) aterros, e edificações, advindas de ações privadas e setores hegemônicos da sociedade.

Com a leitura do plano urbano (vias e ocupação), a análise urbana identifica e categoriza um período na região estudada onde a estagnação de investimento público foram determinante no crescimento urbano na região. $\mathrm{Na}$ década de 80 e 90, com a consolidação do tecido urbano os bairros apresentam a categorização de um período morfológico que as permanências do plano urbano e tecido urbano apresentam irrelevante modificações na sua estrutura urbana. Mesmo com as diretrizes do plano diretor de 1977 objetivando a ampliação de vias e projetos executivos para construção de aterro e o adensamento urbano com ocupação de edificações acima de 10 pavimentos, estes não ocorreram conforme o planejamento urbano previsto para a época, este período morfológico a partir da análise da evolução do plano urbano, é confirmado como um período de estagnação, categorizado como $5^{\circ}$ período morfológico. Manifestando na paisagem um novo período morfológico, categorizado como $6^{\circ}$ período morfológico, somente a partir das obras do aterro da Beira mar continental.

Os bairros Estreito e Balneário, só apresentaram significativas transformações urbana, a partir do estabelecimento de construção do aterro da beira mar continental no ano de 2006, que mesmo antes da obra concluída em 2012, já determinava transformações no desenho urbano da região continental, com remembramento de lotes e construção de edifícios altos, evidenciando o início do processo de verticalização que intercorre na região e um novo ciclo de crescimento urbano.

Desta maneira, a transformação urbana que intercorre, elimina da paisagem formas urbanas que revelam a história do lugar, a partir da alteração de vias, demolição de edificações que orientavam e determinavam a identidade histórica dos bairros. Este recente processo de transformação urbana apresenta tipologias-morfológicas que estabelecem a ruptura e transição do $5^{\circ}$ período morfológico para o período morfológico, categorizado como $6^{\circ}$ período morfológico, predominante pelo processo de verticalização.

\section{CONSIDERAÇÕES}

Nos primeiros levantamentos realizados sobre a área, a dimensão de análise que considerou o plano urbano, buscou confirmar a periodização realizada pela análise do processo de formação sócio espacial, que determinou os períodos histórico e com as ortofotos, imagens de satélites, mapas e plano diretores com a identificação dos períodos evolutivos.

A identificação destes períodos, estabelece relação com a evolução do plano urbano e gera informações relevantes para compreender o processo de construção da cidade e as transformações que determinam os períodos morfológicos a partir das novas formas urbanas construídas na paisagem, visando ações de planejamento urbano que garantam melhor qualidade dos espaços da cidade, bem como a preservação da historicidade do lugar.

\section{REFERÊNCIAS}

COSTA, Staël de Alvarenga Pereira, A morfologia dos tecidos urbanos de influência inglesa da cidade de Nova Lima, Revista: Paisagem Ambiente: esnsaios - n. 25 , São Paulo, p. 55-76, 2008

COSTA, S. de A. P. e NETTO, M. M. G, Fundamentos de Morfologia Urbana. Belo Horizonte: C/Arte, 2015.

LÉFÈBVRE, H. A Revolução Urbana. Belo Horizonte: EDUFMG, 1999. 
LÉVY, Albert. Formes urbanies et significations: revisiter la morphologie urbanie, Espaces et societés 2005/3 (n¹22), p.25-48.

PMF, Prefeitura Municipal de Florianópolis. Geoprocessamento corporativo. Florianópolis, 18 set 2017. Acessado em 18 set 2017. On line. Disponível em: http://geo.pmf.sc.gov.br

REGO, Renato Leão e MENEGUETTI, Karin Schwabe. A respeito de morfologia urbana. Tópicos básicos para estudos da forma da cidade. Revista Acta Scientiarum Technology, Maringá, v. 33 n. 2, p. 123-127, 2011

SANTOS, M. Técnica, Espaço, Tempo: Globalização e Meio Técnico Científico Informacional. São Paulo: Hucitec, 1994.

SOARES, I. Estreito, vida e memória de um bairro. Florianópolis: Fundação Franklin Cascaes, 1990.

WHITEHAND, J.W.R. Conzenian Urban Morphology and Urban Landscapes. In: 6th International Space Syntax Symposium, İstanbul, 2007, Proceedings... İstanbul: Faculty of Architecture of Istanbul Technical University (ITU), 2007. 